\title{
CEO speeches and safety culture: British Petroleum before the Deepwater Horizon disaster
}

\author{
Joel Amernic \& Russell Craig
}

\begin{abstract}
This paper explores the relationship between leadership language and the safety culture at British Petroleum [BP] prior to the April 20, 2010 Deepwater Horizon explosion in the Gulf of Mexico. The discursive construction of important aspects of safety culture in a large, risky, global company such as BP is a central feature of the CEO's role. Using a social constructionist perspective, we conduct an interpretative close reading analysis of the speech of BP's [then] CEO, Tony Hayward, at the Annual General Meeting of BP on April 15, 2010. We also analyse the transcripts of 18 other speeches Hayward delivered before the Deepwater Horizon explosion. We find that the language used contributed rhetorically to an ideology of economic efficiency and cost control, in a manner that was inconsistent with an enduring safety culture. We highlight important insights that close reading analysis of the narrative in CEO speeches can provide to help understand a corporation's ambient safety culture.
\end{abstract}

Keywords: Safety culture; BP; CEO speeches; Annual General Meeting 


\section{Introduction}

At 9:45 pm on April 20, 2010, an explosion rocked the British Petroleum [BP] Deepwater Horizon oil drilling platform anchored about 41 miles off the coast of Louisiana in the Gulf of Mexico. Eleven workers were killed and many others were injured (Elkind et al., 2011). The resultant oilspill from the ruptured wellhead was described by [then] U.S. President Obama as 'the worst environmental disaster America has ever faced' (Obama, 2010).

In this paper we explore roles that CEO language played in contributing to, or detracting from, the ambient safety culture at $\mathrm{BP}^{1}$ preceding the Deepwater Horizon disaster. Directing attention to CEO language is consistent with the view that 'the words used by a CEO constitute an asset' (Leibbrand, 2015, p. 45) in strategic communication. Even more importantly, they can reveal important aspects of the CEO's leadershipthrough-language (Amernic and Craig, 2006). We focus particularly on the prepared speech of the CEO at BP's annual general meeting (AGM). In doing so, we offer an example of the benefit of according serious attention to a neglected medium - a CEO's AGM speech. We refer to CEO language as CEO-speak, consistent with the terminology of Amernic and Craig (2006).

\footnotetext{
${ }^{1}$ Although the physical platform was legally owned (and to an extent) serviced by legal entities other than those in the BP group, BP was the controlling power in the supply chain. This paper focuses on the tone set by the CEO of the dominant business entity involved, BP, regarding the discursive construction of safety.
} 
Our primary focus is on the speech delivered by BP's CEO Tony Hayward to the company's 2010 AGM, held five days before the disaster. In doing so, we draw attention to a particular accounting-related aspect of the narrative: the tension between economic efficiency (including cost control) and the desire for a strong safety culture. Though Hayward claimed that his 'number one priority' was safety, perversely 'safety' is hardly mentioned at all, while cost cutting, financial matters, and organizational efficiency dominate. We highlight Hayward's strong focus on cost cutting, financial matters and organisational efficiency. We also compare the intertextual dynamic between Hayward's speeches during his tenure as CEO of BP before the 2010 AGM, and the speeches of his immediate predecessor from 1997 to 2007, Lord Browne of Madingley.

The specific research question we address is: 'Did the language used in the AGM speech by BP CEO Hayward five days prior to the Deepwater Horizon disaster reflect a tone at the top of BP that was inconsistent with an enduring safety culture?' Our interest centres on understanding how CEO-speak influenced, or reflected, BP's safety culture at the time of the explosion.

We respond to calls by Beelitz and Merkl-Davies (2012), Brennan and Conroy (2013), Craig et al. (2012), and Amernic et al. (2007), for close analysis of the written and oral discourse of powerful business leaders. Additionally, we are motivated by the prospect that analysis of the 'organizational talk' (Rasmussen, 2011) of CEOs of major 
corporations (such as in their public speeches) can 'provide a window on the culture [of an organisation] and its approach to safety' (Ocasio, 2005, p. 118).

A focus on safety seems long overdue in the accounting literature. The substantial literature on social and environmental accounting features many references to the importance of safety-related disclosures and accountability. Yet, a search using Google Scholar reveals that the word 'safety' does not appear in the title of any article published in a major peer-reviewed scholarly journal in accounting.

Nonetheless, the accounting-related literature on safety is not silent. For example, in the business ethics literature, Beelitz and Merkl-Davies (2012) analyse how CEO discourse was used to restore legitimacy after a major accident at a nuclear power plant in Germany. Amernic et al. (2010) explore language and leadership (including safety) issues at BP through the lens of the BP CEO's annual report letters to shareholders from 1998 to 2006. Amernic et al. (2012) discuss pre-disaster financial reporting implications for a reporting entity (BP) with an inapt safety culture.

In the decade prior to the Deepwater Horizon explosion the language of BP's top management did not reflect a strong safety culture. Interest in safety at BP was linked inextricably with, and subsumed by, a broader organisational culture that stressed achievement of operational efficiency. BP's broader organisational culture arose from a strong emphasis on the pursuit of cost efficiency and profits. The discourse of BP CEOs Hayward and Browne suggests that BP paid only trivial attention to safety. 
This paper is organised as follows. Section 2 reviews relevant literature, proposes a working definition of safety culture, and proposes metaphor, ideology and rhetoric as an analytical framework. Section 3 explains some relevant aspects of BP's context at the time of the Deepwater Horizon disaster. It also links the potential influence of CEOspeak to the safety culture of a complex organization, and highlights the importance of the CEO's AGM speech. Section 4 explains the research method and data sources. Section 5 analyses Hayward's speech at BP's AGM in 2010, and links our observations back to theoretical concerns with metaphor, ideology and rhetoric. Section 6 discusses the results further and offers some conclusions. Throughout the paper we adopt a social constructionist perspective, with the intent to highlight three constructs (ideology, rhetoric and metaphor) and the interplay among them.

\section{Analytical framework: Safety culture, metaphor, ideology and rhetoric}

\subsection{Safety culture}

'Safety culture' has been defined in numerous ways. Turner and Gray (2009, p. 1259) observe that although 'safety is largely characterize[d] ... as a disembodied, tangible and easily quantifiable phenomenon' there are many 'contested meanings of safety' (p. 1261). Edwards et al. (2013), Choudhry et al. (2007), and Guldenmund (2000) reveal the ambiguity and contestability of the general concept of 'culture', and 'safety culture' more particularly. Antonsen (2009, p. 184) has drawn attention to the 
'considerable [on-going] disagreement and confusion about what safety culture really is...' Ocasio (2005, p. 120) points out that the Columbia [space shuttle] Accident Investigation Board Report in 2003 did not define the terms 'safety' or 'safety culture.' Rather, in a simplistic and perhaps naïve way, it treated these terms implicitly as 'objective and unproblematic.' Below we review recent debate regarding the definition of 'safety culture.' We then propose a working definition.

Silbey (2009, p. 343) conceived safety culture as 'causal attitude', as 'engineered organization', and as 'emergent.' She argued that the first two perspectives '... reproduce individualist and reductionist epistemologies that are unable to reliably explain social or system performance' (p. 343). As a consequence, she noted that safety culture is often ... measurable and malleable in terms of the attitudes and behaviors of individual actors, often the lowest-level actors, with least authority, in the organizational hierarchy' (2009, p. 343). Silbey's third conception of safety culture, as 'emergent', envisages a complex system involving '... cultural conflict, competing sets of interests within organizations, and inequalities in power and authority' (2009, pp. 343-4). This conception seems consistent with Haukelid's (2008, p. 417) view that 'safety culture should not be something separate from — or in addition to - an organizational culture.'

Although we do not debate the relationship between 'culture' and 'organizational culture,' we are sympathetic to the emphasis cultural anthropologists Pant and Alberti 
(1997) give to the pervasiveness and process-oriented aspects of 'culture'. They viewed culture as an 'ongoing open-ended process' that shapes 'the interplay of interpersonal interactions, biophysical endowments, material situation, social factors and interior dynamism such as values and conscience' (p. 4).

In the safety science literature, Edwards et al. (2013, p. 77) define 'safety culture' as:

... the assembly of underlying assumptions, beliefs, values and attitudes shared by members of an organisation, which interact with an organisation's structures and systems and the broader contextual setting to result in those external, readily-visible, practices that influence safety.

They elaborate three conceptualizations of 'safety culture.' First, their anthropological conceptualization views safety-related outcomes as emerging from 'shared beliefs and values'. Second, a normative conceptualization views safety culture as emerging principally from organizational and management level structures, systems and policies. Third, a pragmatic conceptualization recognized the importance of relating 'beliefs, attitudes, values and contextual factors ... directly to practices which influence safety' (Edwards et al. 2013, p. 77, italics applied)

None of the preceding definitions is completely persuasive or encompassing. Nonetheless, we draw from them to propose a tentative definition of 'safety culture' that has many of their elements - and which accords CEO-speak a critical role. We regard safety culture as 
... the ongoing construction of underlying assumptions, beliefs, values and attitudes shared by members of an organization in moving to an environment characterized by a quest for an absence of harm.

We focus on the safety discourse of a corporate leader of a global corporation. Thus, our standpoint on 'safety culture' is positioned, from a social constructionist perspective, within literature that acknowledges differentiated logics, power and ethics of a global organization. In the safety science literature, Blazsin and Guldenmund (2015) focused attention on the safety culture of 'a big gas distribution company' from such a perspective. Although the company they studied was not global (thus, unlike BP), it was sufficiently large and differentiated that 'a multiplication of realities is generated, reducing the intelligibility and the rhetorical efficacy of the singular "voice from the top"' (Gergen, 2001, p. 142). This 'multiplication of realities' seems to have been even more pronounced in $\mathrm{BP}$, because it is a huge global organization.

Berger and Luckmann's (1966) model of 'cultural development as a continuous cycle' is adapted by Blazsin and Guldenmund $(2015$, p.18) in their discussion of safety culture. They argue that 'sensemaking and simultaneous construction of reality appear as ongoing, dynamic, never-ending processes' (p. 18), characterized by four recurring stages: 
1. 'Experimentation.' This involves 'Individual perceptions of reality and sensemaking.' Individuals (as sensemakers) perceive 'what ... is risky and safe behavior.'

2. 'Interaction.' This involves 'Mutual adjustment of perceptions ... development of standard behaviours and understandings'. The focus is on 'objectivations of subjective process (and meanings) by which the intersubjective commonsense world is constructed' (Berger and Luckmann 1966, p. 33). Interaction results in the development of a safety culture that has 'shared understandings, such as standards of behavior, roles and norms (Blazsin and Guldenmund, 2015, p. 18).

3. 'Institutionalization.' This involves 'Establishment of norms, institutionalization of behavior and expectations', so that 'the reality of everyday life becomes...objectified' (Berger and Luckmann (1966, p. 35). This is represented in a safety context by 'the formal processing of standards and norms...' (Blazsin and Guldemend (2015, p. 18).

4. 'Internalization.' This involves 'Basic assumptions, agreement over the best (only) way of doing things.' This stage is characterized by 'Members of the group shar[ing] a comparable understanding of ... the part of reality the group acts on' (p. 18).

A large, global enterprise such as BP has numerous 'groups' of people engaged in heterogeneous work, with widely different degrees of safety risk. These risks arise, in part, because of heterogeneous already-existing legacy cultures from the broader societies in which they operate, and from the legacy cultures of companies which BP has acquired. As a consequence, the social construction of a unitary, organization-wide 
safety culture is rendered problematic. We are concerned to understand, critically, how the top leadership of such a global enterprise adds to, or detracts from, at least partly, the social construction of safety culture. In this, we expect management control mechanisms (such as budgets and compensation incentives) to influence 'individual perceptions of reality and sensemaking' regarding safety (Blazsin and Guldenmund, 2015 , p. 18). However, the safety discourse of corporate leadership (insofar as it influences such management control mechanisms) is important too.

We draw on the triptych of metaphor, ideology, and rhetoric (discussed below) to critically interrogate the safety discourse in the CEO-speak of top management at BP. Amernic and Craig (2001) elaborate on the deployment of aspects of this triptych in interrogating CEO discourse.

\subsection{Metaphor, ideology and rhetoric}

Tinker (1996, p. 365) noted that 'certain metaphors transport especially powerful biases, because of the way they camouflage the social underpinnings of the reality to which they refer'. Such camouflaging by 'certain metaphors' creates fertile ground for the notion that ideology comprises abstractions and ideas that 'men and women live by, and will occasionally die for' (Eagleton 1991, p. xiii). In a similar vein, Fairclough asserts that 'different metaphors have different ideological attachments' (1992, p. 100). Thus, 
the ideas of metaphor and ideology are linked in a way which, at times, may be conscious, and at other times, less-than-conscious.

In response to a self-posed question, 'What is ideology?' Eagleton (1991, p. 1) declared that 'nobody has yet come up with a single adequate definition of ideology.' $\mathrm{He}$ catalogues numerous 'definitions of ideology currently in circulation' (p. 1). A descriptive exploration of ideology emphasizes 'sensemaking' (Weick, 1995). Critical approaches to exploration of ideology (of the type we engage in) emphasize questions such as those proffered by Lye (2008, unpaginated, with some slight abridgement):

Question 1: What are the assumptions about what is natural, just and right?

Question 2: What (and who) do these assumptions distort or obscure?

Question 3: What are the power relations? How are they made to appear as if they are normal or good? What negative aspects are excluded?

Question 4: Which of the binary oppositions (good/evil, natural/unnatural, tame/wild, young/old) is privileged; and what is repressed or devalued by this privileging?

Question 5: What people, classes, areas of life, experiences, are 'left out', silenced?

Question 6: What cultural assumptions, and what 'myths' [or broad cultural meaning] shape experience and evaluation?

Question 7: What enthymemes [statements which exclude the expression of key assumptions which ground conclusions] can you see in the 'logic' of the text?

Question 8: How does the style of presentation contribute to the logic of the text?

Question 9: What 'utopic kernel', that is, vision of human possibility, appears to lie at the heart of the understanding of the ideology?

Lye's questions are invoked opportunistically in assessing ideology in Hayward's speech. We recognize that ideology can exist at many levels (such as meta and micro). 
Accordingly, we use synonyms for ideology (such as idea, credo, ethos) in our analysis. $^{2}$

The third component of our linked analytical perspective, rhetoric, is informed by Lanham's elaboration:

We have in the West a venerable tradition of studying how human attention is created and allocated: the 'art of persuasion' which the Greeks called rhetoric. A better definition of rhetoric, in fact, might be 'the economics of human attention-structures,' for whenever we 'persuade' someone, we do so by getting that person to 'look at things from our point of view,' share our attention-structure. It is the nature of human life that attention should be in short supply, but in an information economy it becomes the crucial scarce commodity. Just as economics has been the study of how we allocate scarce resources in a goods economy, we now will use a variety of rhetoric as the 'economics' of human attention-structures. (Lanham, 1993, p. 227; see also Lanham [2006]).

We regard metaphor ${ }^{3}$ to be the lynchpin of the tryptich of metaphor, rhetoric and ideology. Metaphor has the potential to camouflage ideology and its at-times potency in imposing (or at least encouraging) the sharing of 'attention-structures.' The power of

\footnotetext{
${ }^{2}$ A focus on metaphor is consistent with a wide range of literature, especially (but not solely) that of Lakoff and Johnson (1980). Even before this highly influential book, scholarship acknowledged the central role of metaphor. For example, Landau (1961, p. 351) contended that: '...where a metaphor is dominant, it is a very powerful instrument. It structures inquiry, establishes relevance, and provides an interpretive system,' thus contributing to the construction of ideology.

${ }^{3}$ Readers sharing a reviewer's concern about the'thinness of exegesis within the social sciences' regarding metaphor, and the 'extensive and philosophically profound work with metaphor... outside of the social sciences', should consult Ricoeur's 'The Rule of Metaphor' ( first English edition, 1977, bUniversity of Toronto Press, Toronto, ON).
} 
metaphor is often nuanced and 'below the radar' of consciousness. Its power has been addressed in a variety of social settings: for example, in Nazi discourse (Harrington, 1995); in deciphering tacit aspects of narrative in organizational research (Steger, 2007), and in accounting-related discourse (Thornton, 1988; Walters-York, 1996; Amernic and Craig, 2009; Young, 2013). The analysis of metaphor is approachable in a variety of ways. These include focusing on individual instances of metaphor in a text or alternatively focusing on an underlying metaphoric structure of a text. We adopt both approaches, particularly since the instantiation of individual metaphors can assist in recognizing the extended metaphoric structure of an entire text.

Werth (1994, p. 79) comments on what he terms a 'metaphorical 'undercurrent' of a text:

Most linguistic approaches to metaphor provide sentence-level accounts of the phenomenon. But literary metaphor is frequently discursive: there is an entire metaphorical 'undercurrent' running through a whole text, which may manifest itself in a large number and variety of 'single' metaphors.

Blain's (1988, p. 263) analysis of the second volume of Hitler's Mein Kampf highlighted an underlying metaphor that seemingly 'organized' the entire text. Blain concluded that 'text seems to have been organized around a metaphor of a medical diagnosis and cure, a religious rite of guilt and redemption, and a drama of murder/revenge' (p. 265). As another example, Oswald and Rihs (2014) demonstrate the importance of extended metaphor in political discourse. 
Thus, an underlying metaphor (or related metaphors) can frame what seems to be the 'natural' or 'obvious' way of talking, speaking, and writing about a topic, including identifying its problems and solutions (Schön, 1993). ${ }^{4}$ For example, in his study of U.S. policy towards Cuba, Pérez (2008) provides extensive examples to support his contention that a limited set of pervasive and relatively constant metaphors (such as CUBA IS A WOMAN, a damsel in distress) were articulated by U.S. policymakers to justify their actions over many years. Pérez $(2008$, p. 36) contends that with respect to Cuba, 'Metaphorical constructs provided a normative grounding for a version of reality and validation of conduct.'

Thus, metaphor, ideology and rhetoric are intertwined analytical perspectives that can be used to interrogate the speech of BP's CEO to its AGM in 2010. When viewed as linguistic means of contributing to the (social) construction of our previously-asserted definition of 'safety culture', ${ }^{5}$ this triptych supports the importance of metaphor (and

\footnotetext{
${ }^{4}$ This conception of the metaphoric structure of a text can be linked more broadly to the phenomenon of 'discourse' which we do not pursue explicitly here. 'Discourse' is a justly contested word. It can be viewed as a collection of interconnected texts and customs 'that systematically form the objects of which they speak' (Foucault, 1979, p. 49). Phillips et al. (2004) distinguish a 'dominant' discourse as one so widely shared that it becomes the default way of talking, speaking, writing, and thinking about a phenomenon. Ricoeur (2016/1981) explores the distinction between language and discourse in creative depth. He develops the idea that 'It is as discourse that language is either spoken or written' (p. 159).

${ }^{5}$ That is, 'the ongoing construction of underlying assumptions, beliefs, values and attitudes shared by members of an organization in moving to an environment characterized by a quest for an absence of harm.'
} 
underlying metaphor) as a way of assessing the extent to which BP's CEO-speak contributed to, or detracted from, the company's safety culture.

\section{BP's context at the time of the Deepwater Horizon disaster}

\subsection{BP's context before and at the time of the 2010 AGM speech}

Scheff (1997) emphasized the importance of context in interpreting text, whilst acknowledging the impracticality of 'locat[ing] all relevant context' (p. 28). In the following subsections, we document BP's context of unlearned safety lessons, the overriding contextual influence of CEO-speak in constructing safety culture in a company such as BP, the shared ownership environment in which the Deepwater Horizon oil platform functioned, and the specific contextual importance of an AGM.

\subsection{BP's context of unlearned safety lessons}

Most people would expect that large, mature and complex companies engaged in high risk operations (such as BP) ensured they had a strong safety culture. However, safety culture was apparently problematic at BP at the time of the Deepwater Horizon explosion. BP had sustained several major safety crises in the preceding decade: a major oil spill at Prudhoe Bay, Alaska in 2006; and a refinery explosion that killed 15 workers at Texas City, Texas in 2005. BP had sustained many lesser reportable safety breaches too. The company was prompted to commission a safety review of the 2005 
Texas City tragedy (Report of the BP US Refineries Independent Safety Review Panel, January, 2007, hereafter referred to as the Baker Report: accessible at www.bp.com).

Not surprisingly, a few months after the April 20 Deepwater Horizon explosion, in July 2010, Tony Hayward's replacement as CEO, Robert (Bob) Dudley, acknowledged publicly that BP did not have an adequate safety culture prior to April 20, 2010, and that things had to be 'shake[n] up' (Crooks, 2010). BP's safety history gave Dudley good grounds for such a stance. For example, in assessing the causes of the 2005 explosion of BP's Texas City plant, the Baker Report (2007, p. xii) expressed strong concern about BP's lack of leadership in setting '.. the process safety "tone at the top" of the organization and establish[ing] appropriate expectations regarding process safety performance ...' The expression 'safety culture' appeared 382 times in the Baker Report. Consequently, BP's board of directors and top management (and plausibly most people affiliated formally or informally with BP) are likely to have been aware in 2007 of the Baker Report's severe and detailed rebuke of BP for having a deficient safety culture.

BP was admonished at the time in the report of the U.S. Chemical Safety and Hazard Investigation Board [CSB] on the Texas City refinery explosion. In respect of BP's safety culture, the CSB concluded that:

The BP Texas City tragedy is an accident with organizational causes embedded in the refinery's culture ... 
- BP Texas City lacked a reporting and learning culture. Reporting bad news was not encouraged, and often Texas City managers did not effectively investigate incidents or take appropriate corrective action.

- BP Group lacked focus on controlling major hazard risk. BP management paid attention to, measured, and rewarded personal safety rather than process safety.

- BP Group and Texas City managers provided ineffective leadership and oversight. BP management did not implement adequate safety oversight ... (CSB 2007, p. 179).

The lessons from the 2005 Texas City explosion and many other safety crises at BP had not permeated the company at the time of the 2010 Deepwater Horizon disaster. According to Steffy:

Despite Hayward's vow to make safety a priority, and despite all the proclamations of the 'new BP' ... its management structure was still convoluted, accountability was hard to find, decisions were made by committee, and cost cutting and financial performance continued to overshadow operations ... (2011, p. 160).

Support for Steffy's assessment is provided in the opening statement of William K. Reilly, co-chair of the U.S. National Commission on the Deepwater Horizon Oil Spill and Offshore Drilling, to that Commission on November 9, 2010:

We know a safety culture must be led from the top and permeate a company. The Commission is looking beyond the rig, and not just to yesterday and what happened on April 20th, but to the months and years that preceded it. BP has been notoriously challenged on matters of process safety... 
Other companies may not be so challenged (Reilly 2010, p. 9, lines 14-20, transcript, Day 2 of fifth meeting).

Farley, a lawyer assisting the Baker panel, recommended that one of the "core elements for a successful safety culture' was the adoption of ' $\ldots$ the right tone at the top.' He made it clear that 'safety' is a core value and involves sending a highly visible message, beginning with the board and continuing down the line. Upper management must then 'walk that talk" (Sissell 2010, p. 39). This emphasizes the strong potential for CEO-speak to help construct 'the right tone at the top' and to enshrine safety as an ongoing, core organizational value - a matter we address in the following subsection.

\subsection{The role of CEO-speak in discursive construction of a safety culture}

CEOs of large, complex, risky organizations have a pivotal influence on safety issues because of their rhetorical contribution to discourses on safety culture. Thus, CEO-speak is potentially a central formative element in developing a safety culture. The language of CEOs can be conceptualised as anthropological because of its importance in propagating and enabling 'shared beliefs and values' (an ideology) relating to safety (Edwards et al., 2013). Such a view is consistent with Schein's (2004, p. 225) contention that 'Culture is created by shared experience, but it is the leader who initiates this process by imposing his or her beliefs, values, and assumptions...' CEO-speak is a primary means of such imposition. 
CEO speeches and other discourse opportunities can also reflect a normative conceptualization of safety culture (Edwards et al., 2013). This is because of the potential for CEOs to talk and write about safety and various structures, systems and policies (for example, by favorably describing management incentive schemes that reward safe behavior). As well, CEOs are often pragmatic in talking and writing about specific practices that are designed to enable safety (Edwards et al., 2013). The earnestness and clarity of such talking and writing indicates whether safety is an 'overriding commitment' (Hopkins, 2006, p. 876). Also important is the 'vocabulary of safety leading' (Ocasio, 2005): that is, the interrelated set of words used to guide organizational communications by the CEO regarding known and unknown risks and danger (such as with respect to BP's hydrocarbon exploration, extraction, transportation, and distribution activities).

Thus, the written and verbal language of a CEO has strong potential to affect various dimensions of the ongoing construction (or destruction) of a safety culture. Through their discourse, CEOs should endeavor to create a climate in which their organization actively develops a safety culture mindset. They should encourage strong aspirations to achieve an 'absence of harm' environment (for persons inside and outside the organization). The 'tone at the top' that CEO-speak renders has strong potential to reinforce a safety consciousness mindset and a commitment to the idea of movement towards the absence of harm. 


\subsection{Safety in a shared environment}

At the time of the Deepwater Horizon explosion, the drilling vessel was owned by another company (Transocean). Key functions were performed by other companies (e.g., Halliburton). Nonetheless, in such a high-risk shared environment it was clear that BP (as the operator of the platform and dominant player) would bear the primary portion of risk, and thus be the primary responsible party for ensuring safety. ${ }^{6}$

\subsection{Importance of the CEO's AGM speech}

An AGM is 'an essential aspect of corporate governance' (Apostolides, 2010, p.140). It provides an 'opportunity to communicate directly with all shareholders ...the whole Board attends ... and is available to answer questions from shareholders present' (Tesco Annual Report, 2008, p. 24). However, shareholders are only one of many groups interested in the speech of the CEO of a large, risky and complex organization

\footnotetext{
${ }^{6}$ Evidence supporting such a view is provided by Tony Hayward's deposition for the trial held in the New Orleans U.S. District Court regarding the explosion. The following exchange took place between Hayward and Roberts, his interrogator (pp. 558-559, Hayward Deposition, http://www.mdl2179trialdocs.com):

Roberts: In general, what was the industry allocation of environmental risk between an Operator such as BP and subcontractors who worked for the Operator while drilling wells for the Operator? Hayward: The industry norm would be, in most circumstances, that the Operator would take that risk.
}

The responsibility of BP in the specific instance of Deepwater Horizon is also evident in the September 4, 2014 finding of Judge Barbier in the US District Court (Eastern District of Louisianna). Barbier found that BP was grossly negligent in the disaster, and even under the restrictive rules of general maritime law, BP was 67\% responsible (Gilbert and Scheck, 2014). 
delivers at the AGM. A range of other stakeholder groups (including employees, unions, activists, competitors, and the public-at-large) also are attentive to the words of the CEO in the high-profile setting. The CEO's speech at an AGM should be recognised as an integral part of what makes an AGM 'a primary vehicle for perpetuating ... corporate culture' (Schneider, 1998, p. 294).

In presenting a speech to the AGM, a CEO can help stakeholders construct meaning by identifying, labeling, and organizing phenomena (such as events and ideas), including strategies and performance measures (Weick and Sutcliffe, 2007). Whatever the CEO includes (or excludes) in the AGM speech deserves to be noticed. The speech is not merely a ritual. It is 'a powerful setting for accountability' (Catasús and Johed, 2007, p. 173). Thus, speech transcripts are an important artifact that can provide insight to an organization's safety culture (Guldenmund, 2000, pp. 251-2). ${ }^{7}$

The 2010 AGM speech delivered by Hayward was his third such speech. Thus, he was a relatively seasoned CEO when this speech was crafted and delivered. It offers potential to understand leadership-through-language, particularly with respect to safety matters, and to assess whether Hayward contributed positively or negatively to the ongoing construction of BP's safety culture.

Since we analyse Hayward's AGM speech as a means of better understanding safety culture at BP, additional justification is proffered to sustain our decision for such a

\footnotetext{
7 We do not analyse aspects of the physical delivery of a speech (gestures, intonation, use of visual aids). Weacknowledge that they are also critical to a complete understanding (Palaima, 2009).
} 
focus. We are mindful of the comment of an anonymous reviewer that 'private or internal discourse, or at least public discourse targeted to other/additional audiences perhaps [might be] more appropriate for this analysis.' Notwithstanding that all of these examples of other 'discourse' genres are likely to be appropriate, we contend that the AGM speech is at least as apt (if not even more so), for gaining insight to the social construction of a company's safety culture. This is so since the CEO's speech to the AGM of a large, multinational company pursuing risky endeavors (such as BP) has the following attributes:

- it is delivered at the AGM, a high-profile setting, watched by various media and others, including other stakeholders;

- it is delivered by the CEO, the most important leader of the company; -the CEO is often the 'face' of the company to the outside world; and -the CEO is also the 'face' of the company to the many heterogeneous constituencies within the company.

Porter and Nohria's (2010) study of the CEO's role in large, complex organizations, captures the importance of CEO language. They claim that '...the CEO's job is inherently one of communication...' (p. 464). Because of the importance of the discourse setting in which it takes place, the CEO's communication at the AGM is plausibly one of the pinnacle aspects of the CEO's 'job.' We that other external and 
internal discourses would, in other research, provide important additional insights to corporate leadership.

\section{Method and data}

We reviewed the 18 public speeches Hayward delivered as CEO of BP before BP's 2010 AGM. These provide context for a more intensive examination of his speech to the 2010 AGM. His 18 prior public speeches are insightful since 'the speaker's life, insofar as it is public, forms a long prelude to his speech' (Perelman and Olbrechts-Tyteca, 1958, p. 320). Appendix A summarises the date, title, venue, and number of words in each of Hayward's 18 prior speeches. We also briefly examined the text of the 125 speeches presented by Hayward's predecessor as CEO of BP, Lord Browne of Madingley.

Examination of Hayward's 18 prior speeches focuses initially on the keyword 'safety.' We also investigate whether the keyword 'culture' is used in the context of safety. Both of these keywords have significant rhetorical potency (Hart et al., 2005; Williams, 1976). The use of these keywords by a CEO helps discursively to construct a large, complex and risky organization's safety culture, and to indicate that a safety culture is a desired organizational state. As Guldenmund (2000, p. 252) points out, it is a 'good sign' if 'references to safety' are made to be among the 'basic assumptions of 
an organization.' Guldenmund's corollary is that when 'such references cannot be found there is insufficient evidence to conclude that a safety culture exists' (2000, p. 252).

Guldenmund's claims regarding use of the words 'safety' and 'culture' do not necessarily mean that safety culture is, as we suggest, a 'desired organizational state' but that the terms are simply being used strategically. However, support for our stance is provided by Tucker et al. (2016). They report recent evidence that CEOs indirectly, but importantly, influence safety 'by fostering a safety climate in the TMT [top management team] that then trickles down to lower levels in the organization' (p. 1234). We submit that Hayward's use of the keywords 'safety' and 'culture' in his 18 prior speeches is a necessary but insufficient indicator of a 'safety culture'.

In analyzing the 2010 AGM speech, we viewed metaphor as being intertwined with rhetoric and ideology. We are alert to the challenges involved in exploring metaphor in the speech. a prominent contributor to the metaphor literature, Gibbs, highlights the need for caution :

'... counting metaphors ... do[es] not tell us much about the degree of metaphoricity within any word or longer stretch of discourse. Moreover, even a single verbal metaphor can provide structure for an entire discourse where the main metaphorical theme is elaborated upon through nonmetaphorical language. There are also many occasions in which the entailments of underlying conceptual metaphors ... reflect a metaphorical conception of some idea despite the fact that the language giving evidence of this is not metaphorical ... there may be few instances of verbal metaphor yet the 
main ideas communicated still express an overall metaphorical understanding of some idea or event (2015, p. 175).

Mindful of the above, we do not overemphasize 'linguistic instances of a metaphor, while overlooking the importance of the logic of the metaphor in the context of the passage" (Rohrer and Vignone, 2012, p.13).

The 2010 AGM speech was examined by both authors using a close reading approach. As with Amernic and Craig (2006, p.6), the transcript was subjected

... to multiple (usually three) close readings, conducted from different (but mutually reinforcing) perspectives. Each close reading constitute[d] an intensive, almost forensic, scrutiny of the explicit and implicit composition of the text ... typically ... one close reading for ideology, one for rhetoric, and another for metaphor.

Each author separately read the text of the speech several times, making working notes. These were exchanged, reviewed, and a consensus was developed over several iterations of this process. Readers should acknowledge that close reading methods are interpretive and not limited by the capacity of close readers to contextualize and interpret 'words on a page' in an unbiased fashion. Thus, whilst an interpretive process can produce many useful insights, it can also lead to contestable conclusions because of the complexity of a social phenomenon and a 'plurality of plausible explanations' 
(Ron, 2008, p. 291). We do not claim that the explanations we offer are necessarily unique or better than some others. Since knowledge of the social world is constructed socially, the views we present are a matter of intersubjective agreement; and the resulting knowledge is an interpretation which is subject to social controls, criticism by peers, and social (re)-negotiation (Blaikie, 2007).

In Appendix B, we reproduce Hayward's speech to BP's AGM held on April 15, 2010, in London. The speech comprised 2323 words. Line numbers have been added to facilitate analysis. Our multiple close readings of this speech involved slowing down the reading process in a search for implicit assumptions, ideology, silences, techniques of argumentation, and important cognitive features, such as metaphor. This involved carefully re-reading sentences and paragraphs; exploring the sequence and frequency with which ideas and words were used; reading complex text phrase-by-phrase to discern meaning; and reflecting on how various facts, text or arguments co-relate. As we read text, we marked passages where appropriate, investigated the meaning of individual words, looked for apt and inapt juxtapositions, and sought insights to authorial intent. Like Slagell (1991, p. 156), we sought to understand the 'inner workings' of text. Our particular intent was to study how the tryptich of metaphor, rhetoric and ideology constructed meaning in terms of safety.

We focus on the parts of Hayward's 2010 AGM speech in which he refers directly and indirectly to safety. We were aware of BP's poor safety track record at the time of 
the speech, and the company's alleged renewed concern for safety. Thus, we expected to observe strong explicit mentions (and subtle implicit instances) of espoused values and attitudes regarding safety. We also expected to find strong 'secondary articulation and reinforcement mechanisms' (Schein, 2004) - such as safety-related aspects of organizational design, systems, procedures and rituals; and some formal statement of organizational philosophy or creed relating to safety.

We present results in the sequence in which associated text occurs. We do not cluster results into identifiable themes or discourse features (such as metaphors, silences, implicit assumptions). Our decision to opt for the former approach is consistent with many similar studies (for example, Slagell, 1991; Amernic and Craig, 2013) and is based on belief that sequence of narrative is critical in making sense of text.

\section{Results}

\subsection{Speeches of Hayward and Brown prior to the 2010 AGM}

The word 'safety' appears only 17 times in Hayward's 18 speeches prior to his 2010 AGM speech. (For details of these speeches see Appendix A). The incidence of the word 'safety' is low considering BP's longstanding poor safety history. Thus, there is little support for the notion that the tone at the top was engaged actively in a normative discourse to promote a safety culture. For example, Hayward mentions 'safe(ty)' in

referring to a corporate project (speech \#3); safe(ty) (of) oil supplies (speeches \#4 and 
$\# 18$ ); and the title of a BP report (speech \#10). The word 'culture' appears only four times in Hayward's public speeches. Each use is bereft of any link to safety.

These results are not surprising given that Hayward's predecessor as CEO of BP, Lord Browne of Madingly, used the word 'safety' only 56 times, and the word 'safe' only 15 times, in the 332,847 words comprising his 125 available public speeches during his tenure as CEO from 19 May 1997 to 26 April 2007. (These speeches were downloaded from the BP website, www.bp.com, in 2007). In contrast, Browne used the word 'cost' 224 times: that is, 15 times more often than 'safe(ty)'. Browne used 'culture' 39 times, but in ways unassociated with safety or with words related to safety.

\subsection{Close reading of CEO Hayward's 2010 AGM speech}

We present the results of our analysis of CEO Hayward's 2010 AGM speech in twenty 'observations.' These are arranged sequentially, based upon the text of the speech. Our close analysis of text begins with lines $62-66$. We use the acronym TH to refer to Tony Hayward.

\section{Lines 62-66}

Our priorities which lie at the heart of all our operations remain safety, people and performance. This is what we call our Forward Agenda. Our focus on safe and reliable operations is now strongly embedded in all our businesses; we are continuing to build the on [sic] the core capabilities of our people; and 
we have started to see the benefits of improved operational performance flowing through to the bottom line.

Observation \#1. Safety, people, and performance are said to be positioned 'at the heart of all our operations.' The 'heart' metaphor evokes emotion, emphasizes the centrality of safety, people and performance, and is an astute rhetorical move. Hayward's mention of 'safety' before 'people' and 'performance' seems to be a positive indicator of the rhetorical construction of a safety culture (consistent with Guldenmund, 2000, p. 252, and our earlier discussion). The use of the modifier 'remain' implies that that such importance was always the case and continues to be so. However, the use of 'now' in 'Our focus on safe and reliable operations is now strongly embedded in all our businesses...' implies that the 'focus on safe and reliable operations' was perhaps not 'strongly embedded' previously. So, we have an inconsistency between the words 'remain' and 'now.' Furthermore, by listing 'safety', 'people', and 'performance' separately, TH apparently regards safety as a separate, perhaps compartmentalised construct. This is inconsistent with the view that safety culture is an 'integral constituent' of an organization's culture (Haukelid, 2008, p. 417). In Lye's (2008) terminology regarding ideology, TH's apparent compartmentalizing is an assumption 'about what is natural, just and right.'

Further, who are the 'people' to whom TH refers? Are all people, including all possible stakeholders in BP (including those who might have their lives ruined or at 
least disrupted by the company's operating activities)? Or are they restricted to shareholders and (perhaps) employees? Lye's (2008) question 5 regarding "What people....are 'left out", seems apt here.

Observation \#2. TH tells us that 'our focus [is] on safe and reliable operations.' However, the many focuses noted by $\mathrm{TH}$ in the speech dilute the rhetorical effectiveness of the word 'focus'. In lines $85-86$ for example, we are told BP is 'focusing on deepening our capability by putting the right people with the right skills in the right place.' In lines 113-114, the 'focus' on 'efficiency' is a 'steadfast' one. The power of the adjective 'steadfast' suggests that 'efficiency' is a primary focus. But can such a focus on efficiency be reconciled with the 'safe and reliable operations' mentioned in line 63 ? Since the word 'focus' is metaphorical, and implies a unitary directed attention, a complex multinational company such as BP must necessarily establish organizational infrastructure and management control systems to effect such multiple focuses in meaningful ways. But there is no mention of such systems in the speech. Use of a 'focus' metaphor throughout the speech seems consistent with the conception of rhetoric as sharing 'attention-structure' (Lanham, 1993). TH is telling his audience what is being focused upon, but glosses over the problematic nature of the focusing. 
Observation \#3. The metaphor of 'building on the core capabilities of our people' provides a bridge from Hayward's 'safe and reliable operations.' It establishes a causal link with 'the benefits of improved operational performance flowing through to the bottom line.' Thus, safety is made rhetorically subservient to 'improved operational performance.' he ultimate criterion is apparently 'the bottom line' [profit performance]. According to Lye's (2008) question 4, this indicates a privileged binary, ideologically. This chain of metaphors seems fundamentally at odds with the (absent) rhetorical construction of 'safety culture.' TH's silence about the measurement and 'benefits' of 'improved operational performance' is an implied call for faith in what he says. 'Improved operational performance' evokes an engineering perspective. The metaphors in the phrase 'and we have started to see the benefits of improved operational performance flowing through to the bottom line' intriguingly include the construct of 'flowing through'.

Lines 62-66, overall, offer tepid support for Edwards et al.'s (2013) anthropological conceptualization of 'safety culture,' In which safety-related outcomes are regarded as emerging from 'shared beliefs and values' (p. 77).

\section{Lines 70-73}

Safety remains our number one priority and l'm pleased to report we can see clear progress. There has been a significant reduction in the frequency of recordable 
injuries and the number of major incidents related to integrity failures has also fallen. At the same time we're reducing containment losses in our operations.

Observation \#4. Even though it is alleged that 'safety remains our number one priority', the criteria for 'we can see clear progress' are based solely on implied output measures. A comparison of the facts provided regarding safety, and the facts reported later in the speech in respect of financial performance, is telling. Hayward cites 24 performance measures in his AGM speech (see Table 1, below). However, only one of these ('recordable injuries', line 71) refers to safety. This sits oddly with the foundation concepts of safety culture suggested by Silbey (2009) and Antonsen (2009). There are many questions $\mathrm{TH}$ might reasonably have been expected to touch upon. Is safety genuinely better? Is there a culture of operational safety exemplified by safety meetings, and rewards for safety improvement suggestions? How is safety embedded in employee compensation systems? What influences on safety did the Baker Report and other reports have? Is the 'significant reduction' significant in a statistical sense? What does 'integrity failure' mean here?

From the perspective of Lye's (2008) question 1, lines 70-73 imply that it is 'natural, just and right' to assume safety is a construct that can be largely monitored and measured by reductionist output indicators. Such indicators, if well-designed, are important, and should function within a safety culture (Edwards et al., 2013). 
Observation \#5. Safety is identified as 'our number one priority.' Paradoxically, the word 'safety' is used only twice in the entire 2323 words of the speech. The text is dominated by statements concerning financial matters and organizational efficiency. How can safety be 'our number one priority' when it merits only two mentions, and implies a simple view of such a complex concept? TH focuses instead on the financial numbers, and the importance of driving down costs. The emphasis on non-safety performance measures is evident in the summary in Table 1 of the various financial and other (nonsafety) performance measures TH refers to:

Table 1

Performance Measures in Hayward's Speech as CEO to BP's AGM on 15 April 2010

\begin{tabular}{|l|l|}
\hline Performance measure & $\begin{array}{l}\text { Line number(s) in speech } \\
\text { (reproduced in Appendix B) }\end{array}$ \\
\hline cost(s) & $42,54,105,106,108,109,132$ \\
\hline investment & 46 \\
\hline cash flow & 52 \\
\hline recordable injuries & 71 \\
\hline number of major incidents related to integrity failures & $71-72$ \\
\hline containment losses & 73 \\
\hline matching people, skills, places & $85-86$ \\
\hline competitive gap & 95 \\
\hline efficiency & $103,107,114,189,199,202,207$ \\
\hline refining margins & 112 \\
\hline reserves replacement & $125,126,173-174$ \\
\hline production growth & $127,159,161$ \\
\hline headcount & 135 \\
\hline new (oil) resources, projects & 156,164 \\
\hline larger, advantaged refineries & $179-180$ \\
\hline supply optimisation capability & 181 \\
\hline
\end{tabular}




\begin{tabular}{|l|l|}
\hline earnings (return on capital) versus peers & $188-189$ \\
\hline value chain/supply chain performance & 107,190 \\
\hline upstream project execution & 191 \\
\hline safe and reliable operations & $199-200$ \\
\hline clearer accountabilities & 203 \\
\hline standard designs and equipment & 204 \\
\hline new culture & $210-211$ \\
\hline costs, capital efficiency and margin quality & $215-216$ \\
\hline
\end{tabular}

Throughout the speech, there is an apparent privileging of financial performance over safety. This is evident in the overwhelming preponderance of accounting-based and similar performance measures, and the failure to acknowledge the complexity of safety culture as an evolving and ongoing organizational challenge.

Observation \#6. If cost cutting is an over-arching objective as our reading concludes, some tangible justification should be offered regarding how 'safety' is improved, or at least maintained, as costs are cut and numerous other economic performance goals (listed above) are pursued. Such an explanation should reflect the nature of safety culture well beyond mere linkage to myopic metrics such as reportable incidents. TH's pronounced emphasis on non-safety performance measures (as evidenced by the preponderance of financial and economic measures) focuses attention on shared beliefs and values other than safety culture. Thus, Edwards et al.'s (2013) normative conceptualization of safety culture is poorly served, since $\mathrm{TH}$ emphasises performance measures other than safety. Indeed, the great challenge of improving safety whilst reducing costs is not addressed (Lye, 2008, question 5). 


\section{Lines 75-78}

We are continuing to improve our skills and capabilities as we roll out a common Operating Management System across our business. By the end of 2009 we'd fully implemented this at 70 sites - covering around 80 per cent of our operations and the remainder will be completed this year.

Observation \#7. The phrase '...fully implemented... at 70 sites...' is the first achievement noted regarding the Operating Management System [OMS]. Near the end of the speech (lines 210-211), TH refers casually to 'establishing' a 'new culture' at BP. This is the first mention of culture in the entire speech. Yet, creating a new culture is a major challenge that requires substantial effort. Is the idea of instituting in a new culture consistent with such a casual mention? If the CEO refers to this new culture only in passing, what are the prospects it will be taken seriously by employees? TH does not say more about what this 'new culture' is supposed to be, and in what sense it differs from what went before. Indeed, from the perspectives of Pant and Alberti (1997), Schein (2004), and Edwards et al. (2013), the 'new culture' that TH mentions - which presumably includes the OMS as a major structural component - seems curiously unlike a safety culture. Given the numerous financial and economic performance measures mentioned, the apparent hiving-off of safety, and the mention of a safety metric ('reportable incidents') only once, this 'new culture' seems rhetorically and ideologically inconsistent with 'safety culture.' 


\section{Lines 101-103}

The drive to increase efficiency and reduce costs remains a key focus for everyone at BP. We started more than two years ago in our effort to counter cost inflation and drive much greater efficiency into our business.

Observation \#8. The one word metaphor 'drive' appears six times, and 'driving' and 'driven' once each in the speech. These uses provide some insight to TH's approach to leadership. TH cannot conceivably know that 'The drive to increase efficiency and reduce costs remains a key focus for everyone at BP.' Although such hyperbole is (as a reviewer of this paper observed), 'a common aspect of strategic discourse', it nevertheless suggests, at the very least, a desirable vision for TH as CEO.

Indeed, as mentioned above, it is highly unlikely that a firm such as BP can simultaneously drive down costs and improve safety, especially without acknowledging the complexity of constructing a safety culture in which everyone in the company would have a common focus on greater safety at reduced risk (Blaszin and Guldenmund, 2015). This presumes a unitary, mechanical corporate and organizational culture of a type that is unrealistic in a large global, high-risk company. This message from the top is likely to encourage fake feedback systems, such as were reported in Collinson's (1999) study of North Sea oil companies. Further, the 'drive' metaphor is a root metaphor. It suggests that TH's leadership is characterised by a relentless push to 
increase efficiency and reduce costs. Such behavior is in many ways inconsistent with the construction of a safety culture. Overall, lines 101-103, along with other parts of the speech mentioned above, seem consistent with cultural assumptions (Lye, 2008, question 6) that are related to the omniscience of the company's leadership (they seemingly know what 'a key focus for everyone at BP' is and they energize the 'drive').

Observation \#9. There are parallels with the 'faster, better, cheaper' organizational credo (or ideology) introduced at the National Aeronautics and Space Administration [NASA] in the early 1990s. This credo was implicated as a cause of the disintegration of the Columbia space shuttle during re-entry, and the death of seven crew members (see Ocasio, 2005). The apparent mentality reflected by Hayward (which seems to have constituted the managerial ethos at BP) was that oil drilling and refining were inherently and unavoidably risky operations; and, 'while risks must be managed and mitigated, making [such activities] safer was not a priority' (Ocasio, 2005, p. 108). Indeed, in terms of Ocasio's (2005) notion of a 'vocabulary of safety leading', Hayward's speech does not use any safety-related words such as 'risk', 'hazard', 'maintenance', 'repair', 'prevent' or 'accident.' Lye's (2008) question 5 regarding silences seems appropriate here.

\section{Lines 105-110}


In the upstream we are leading our peer group in driving down production costs, with BP's unit costs in 200912 per cent lower than in 2008. We will maintain this momentum through activity choice and in the way we manage the supply chain. In the downstream our efficiency initiatives have reduced cash costs by more than 15 per cent in 2009 and our goal over the next 2 to 3 years is to return costs to 2004 levels. For the group as a whole we reduced our cash costs last year by more than $\$ 4$ billion.

Observation \#10. The stress on 'driving down production costs' suggests a compulsion, metaphorically. What is unsaid is how such 'driving' could be compatible with a safety culture or with enlightened Human Resource Management practices (Lye, 2008, question 5, among others). The claim that BP will 'maintain this momentum through activity choice and in the way we manage the supply chain' is a mechanistic prescription: an engineer's view of the world of BP. Although cost management and economic efficiency are worthy goals, the totalizing rhetoric and ideology of TH'S CEOspeak on these goals is confounding because it constrains the capacity of his 'tone at the top' to construct a safety culture.

Indeed, the 12 per cent reduction in BP's unit production costs in just one year seems astounding. This is left as seemingly unproblematic in the speech (Lye, 2008, questions 1, 4 (lower cost is better?). Accountants and many others know that the word cost and its underlying concepts are far from straightforward. Yet, in TH's speech, no hint of such complexity is evident. We acknowledge that in a high-level speech by the CEO, such inconvenient niceties are acknowledged rarely. However, the magnitude of 
the reduction (12 per cent) deserves commentary. How was it accomplished? Did different production units have different unit cost reduction results? Cost is rendered rhetorically, and ideologically, unproblematic - as is the potential for organizational disruption and safety culture harm arising from such a sudden, large reduction.

\section{Lines 112-114}

In 2009, lower oil and gas prices and weak refining margins created a challenging environment for the whole sector. But the operational momentum in our business and our steadfast focus on efficiency has clearly improved our performance relative to our peers.

Observation \#11. All major oil companies faced 'a challenging environment' due to factors largely beyond their control ('lower oil and gas prices and weak refining margins'). It is difficult to accept that the operational virtuosity displayed by BP (and evidently fashioned by TH and colleagues since 2007) 'has clearly improved our performance relative to our peers' (e.g., Shell, Texaco). We seem invited to believe that BP's peers are less astute and possibly relatively inept. Perhaps 'our peers' didn't drive down costs like BP, or match people and skills like BP? Perhaps 'our peers' are more design-safety conscious and better employers. Or perhaps the invocation of 'competitive talk' and the performance of 'peers' is a way of 'generating consent' and 'discouraging potentially creative stakeholder conflict' (Rasmussen, 2011, p. 474). Thus, 
rhetorically, the implication is that the 'focus on efficiency' is acceptable, and virtuous, because of pressures imposed by the market and competitors.

Observation \#12. The word 'momentum', when allied with many uses of the word 'drive', reinforces the master JOURNEY metaphor. 'Operational momentum' is especially metaphoric in suggesting a large, unstoppable physical object. TH and colleagues in the 'refreshed' top management team (line 84) seem to be claiming recognition for engineering an entity that can progress unimpeded. Additionally, the reference to 'our performance' (line 114) does not seem to include any aspect of safety culture.

\section{Lines 183-185}

However while our portfolio ranks amongst the best in the industry, our financial performance has yet to fully reflect this. There is now a real opportunity to make this portfolio work harder for us and we intend to do just that.

Observation \#13. The expression 'a real opportunity to make this portfolio work harder for us' seems to be a euphemism for 'push operations and safety to the limit in the quest for profits.' Who are the (unmentioned) people in 'this portfolio' (Lye, 2008)? TH seems to be thinking only of shareholders because the identity of 'us' seems apparent in the early framing of the speech. In line 9 , TH states candidly that he wants BP to '... make 
our asset base work harder for our shareholders. ${ }^{8}$ Any CEO discourse which focuses narrowly on 'shareholders' is disingenuous, since the economic welfare of shareholders depends fundamentally on constructing and enabling a robust safety culture (particularly in a risky company such as BP). ${ }^{9} \mathrm{~A}$ recent empirical study concludes that 'firm value appears to decline with injury rates' (Cohn and Wardlaw, 2016, p. 2053), thereby suggesting a relationship between safety cultures and the economic welfare of shareholders.

The use of the apparent metaphor 'portfolio' seems consistent with an ideology that views a company through the lens of corporate finance (Lye, 2008, questions 1, 2). Such a metaphor obscures the complexity and humanity of any business, especially one such as BP. Rhetorically, it seems to signal that BP's leadership adopts such a perspective - one, presumably, thatis consistent with the demands of financial capital. However, such a metaphorical perspective seems inconsistent with the 'embedding' of a safety culture at BP.

Observation \#14. The resoluteness of the rhetorical flourish '... and we intend to do just that' seems ominous. The notions of 'mak[ing] this portfolio work harder' and TH's expressed intent to do so ('we intend to do just that') seem egregiously single-focused.

\footnotetext{
8 It is possible that this 'asset base' included the company's workforce.

${ }^{9}$ BP's shareholders suffered direct economic losses from the explosion and ensuing events. According to Stout (2012, p. 1), the company's suspension of dividends and its share price deterioration resulted in a 'decline of BP's total market value amounting to nearly $\$ 100$ billion.'
} 
Such CEO-speak is not conducive to the promotion of a safety culture. Such a rhetorical flourish seems consistent with 'top-down' management and inconsistent with the ongoing construction of a safety culture.

\section{Lines 187-191}

So how do we define the opportunity? There are many ways to view it: from company-wide issues such as the gap in earnings versus our peers, to return on capital employed versus the competition; and from segment-level issues such as improving refining efficiency and closing the gap in fuels value chain performance in the US to improving efficiency in our drilling and in the execution of projects in the upstream.

Observation \#15. Here TH provides some detail in respect of his assertions in lines 183185. He adopts a reflective, inquisitorial, professorial pose for rhetorical effect. The 'many ways to view it' signal a multiplicity of perspectives adopted by $\mathrm{TH}$ and colleagues. Many of the 'many ways' involve essentially (lagged) accounting performance measures or measures that are largely accounting-based, such as 'improving refining efficiency.' The focus is on technical, economic and financial measures.

Since space and time with respect to a CEO's AGM speech are limited, the items mentioned are important to the speaker. The ways that TH 'define[s] the opportunity', are still many more than one, and this signals that $\mathrm{TH}$ is aware that success, or 'opportunity', can be measured in many ways. This is a good thing when one is talking 
about the performance of a company such as BP. Unlike Enron's leadership, which asserted that the company was 'laser-focused' on the singular and inapt accounting measure of earnings per share (Craig and Amernic, 2004), TH seems more open. However, the list of targets 'exclude the expression of key assumptions which ground conclusions.' Thus, ideologically Lye's (2008) question 7 is relevant here. Most importantly from the perspective of this article, how are these definitions of the opportunity linked to TH's assertion at line 70: 'Safety remains our number one priority"?

\section{Lines 193-194}

Whichever way you look at it, there are significant opportunities for improvement and in every case firm plans are in place to close those gaps.

Observation \#16. TH and his colleagues are again resolute since 'in every case firm plans are in place to close those gaps.' This is top-down leadership, both in defining the gap, and in setting the 'firm plans.' Are the plans negotiated with operating management? Are the plans inflexible? What are these 'firm plans?' The audience should not be satisfied with this underargued and undocumented assertion.

The phrase 'Whichever way you look at it, there are significant opportunities for improvement' seems to acknowledge the multiplicity of ways to set targets and measure performance. Rhetorically, this is a constructive move. However, the key construct 
'improvement' seems limited, as noted above, to traditional accounting, finance, and market constructs. This echoes Lye (2008) questions 1, 2 and 3 in particular.

\section{Lines 196-197}

Our goal over the next few years is to realize the latent potential of our asset base by improving the efficiency and effectiveness of everything we do.

Observation \#17. We are invited to have faith that BP can introduce a wondrous system to effect this promised improvement. There is no hint of magnanimity, reality or humility. Rather, the rhetoric seems intended to induce a generally 'feel good' mood in TH's audience. Presumably, The audience would not be interested in messy details, nor have little interest in exploring the entailments of complex metaphors such as 'latent potential of our asset base.' Implicitly, this singularly limited, unrealistic, and seemingly antihuman rhetoric and attendant ideology seem dysfunctional: all that is alleged to be needed is economic 'efficiency and effectiveness'. The assertion '...by improving ... everything we do' is less-than-realistic and grandiose. Thus, TH's AGM speech has strong traces of a public relations discourse, rather than a credible accountability report.

Lines 218-220 
Of course the future looks challenging. It always does. But we have emerged from 2009 in great shape and with renewed confidence and determination. We can see the prize and we believe we are well positioned to capture it.

Observation \#18. TH frames his conclusion using 'the future' as a metaphor. ${ }^{10}$ The 'of course' naturalises the challenging nature of 'the future' rhetorically, and is further reinforced by 'It always does.' On one level, these are mere empty words (Cheney, 1998). However, rhetorically, their emptiness (or blandness) enables them to carry an unnoticed message: that $\mathrm{TH}$ and colleagues always face the trials offered by an unruly and unpredictable 'broader environment' (line 12). The discursive strategy appears to be to position $\mathrm{TH}$ and his leadership colleagues in a reactive, perhaps forgiving, space - in which they have, at times, little control over this 'challenging future'. The use of 'prize' is curious too. How is the 'prize' defined? Does it include a safer BP, buttressed strongly by leadership and an accommodating pro-active tone at the top? Who are the 'we' who can (metaphorically) 'see' such an ill-defined 'prize'? How will 'we' recognise it? Is a broad range of stakeholders (including 'the public') contained within the 'we'?

\section{Lines 222-224}

I want to thank the employees of BP for their commitment - and I want to thank each of you as shareholders for your loyalty and support. I hope you will continue to support us on the journey that lies ahead. Thank you.

\footnotetext{
${ }^{10} \mathrm{TH}^{\prime} \mathrm{s}$ assertion that '...the future looks challenging' is consistent with McDermott's metaphor of 'the future as challenge' (1990, pp. 192-195).
} 
Observation \#19. This is the only time TH mentions 'employees.' Presumably, they are the 'our people' (referred to at lines 65 and 83). If they are so good at outperforming their peers (lines 112-114), they deserve more mention. When TH mentions people, he seems to be alluding to senior managers. Such an attitude towards the other employees of $\mathrm{BP}$ is consistent with the rest of his speech. Although $\mathrm{TH}$ was formally addressing shareholders, he ought to have been conscious that his speech would have a wider audience than those physically present.

Observation \#20. The speech is dominated by a financial focus. It seems to have a public relations template. There is little genuine concern for 'people issues.' Thus, the words in lines 222-224, and in the speech as a whole, should not be taken literally. CEO-speak, as manifest in a speech to an AGM, is an important facet of leadership in constructing organisational identity (Amernic and Craig, 2006).

\section{Discussion and conclusions}

Through the lens of the triptych of metaphor, ideology and rhetoric, we have highlighted the discourse used by BP's CEO, Hayward, in his April 20, 2010 AGM speech to 'shape' safety culture and develop attitudes to safety. The speech engages rhetorically in attempts at 'sensemaking', constructing intersubjective 'commonsense', establishing institutionalized norms, and promoting an internalization of 'the best way of 
doing this.' But it is disingenuous. It invites belief in an ideology: that BP is going to do what few (if any) corporations can do or have done... drive down costs and increase capital efficiency whilst maintaining a first priority of safe and reliable operations. Does TH really believe BP can do this? Or is he simply telling ostensibly gullible shareholders what he thinks they want to hear? Perhaps his speech is simply corporate jingoism: a deliberately 'upbeat account' (Breeze, 2012, p. 15) and a public rallying cry for the benefit of the managers and board members present?

TH claims to have made BP's 'asset base work harder' (line 9). Through resultant economic efficiency, he claims to have mediated the effects of climate change (line 22, ff.). This is disturbing and misleading. Whereas Hayward is expansive throughout about how and why economic efficiency will be achieved, he does not mention any implications for safety or operational management. Nor does he mention how cutting costs through 'driving down' things will affect safety, employee welfare, job security and good environmental citizenship (all of which plausibly affect safety culture). An implicit taboo here needs deconstructing (Martin, 1990). This is the taboo to never acknowledge the effect on safety of a drive to cut costs and enhance economic efficiency.

It is improbable that any 'drive' to increase efficiency (described variously by $\mathrm{TH}$ as reducing costs, countering cost inflation, driving down production costs, reducing cash costs by $15 \%$, focusing steadfastly on efficiency) would not affect other parts of BP's complex web of operations. Inevitably, there would be disadvantageous flow-on effects 
to one or more areas of safety, employee morale, job security, and the condition of capital equipment. The idea that economic efficiency can be achieved by improving capital efficiency, but without compromising safety in some way, is bold. TH seems obsessed with economic efficiency and beating competitors. Despite TH's platitudes regarding safety, the BP he leads will be 'driven' to cut costs on operations and safety wherever it can. The tone at the top is one of 'join us on a journey to a financial Nirvana - we'll be lean and keen and operationally sound.'

A master metaphor courses through the speech:

\section{BP IS ON A JOURNEY TOWARDS A GREAT FINANCIAL PRIZE}

This is a classic example of the 'wagon train' metaphor, described in the context of labor relations by Dunn (1990). This metaphor is regarded by Amernic and Craig (2006, p. $60)$ to be a journey

... into unknown territory [that must be undertaken] by organized, self-confident leaders and acquiescent non-leaders. They must move forward towards the greater public good. This notion is nicely captured by the ... illuminating image of a 'wagon train' voyaging across the hostile, virtually limitless, American frontier. 
As the text of line 18 suggests, despite the inevitable challenges in the path of the BP 'wagon train', we can rest assured because the 'heroic leader' or trail boss [TH] will get us to our destination. The BP wagon train has moved ahead successfully because BP has 'refreshed' its trail bosses (line 84) and has reviewed its 'whole approach to the organization' of the wagon train (lines 84-85). Furthermore, we are regaled with what an excellent team, organisation and system the BP wagon train has. It has 'closed gaps,' 'restored momentum' and 'grown production' (lines 95-97). Despite this, the BP wagon train is obsessed with its 'track record,' and what other 'wagon trains' (its peers) are doing. The trail boss $[\mathrm{TH}]$ says, 'we can see the prize ... the journey lies ahead' (lines $219,223-224)$. Here the ideological effect of the metaphor and rhetoric are evident. The prize is a reward to capital, not a reward to labour, the environment or social equity. The prize is not an exemplary safety performance or a work environment that represents an absence of harm.

The few references to safety by Hayward in his 19 speeches, including the April 20, 2010 AGM speech (and by his predecessor Browne's 125 speeches delivered during his tenure as BP's CEO) indicates that the concept of 'safety culture' existed in a curious linguistic lacuna in BP's upper management echelon. Hayward and Browne (partly through their discourse) helped to shape a culture at BP that gave short shrift to safety. Indeed, their leadership language (as evidenced in their public speeches) did not reflect the complexity of a safety culture. Rather, the culture they endorsed and 
promoted encouraged greater attention to financial and operating efficiency, and to attendant organisational management control systems and procedures.

An important reminder emerging from our analysis is that words (and other symbols) matter. At times, the words of powerful corporate leaders matter more than most. As a reinforcing and concluding codicil, we draw attention to the words used in a speech to the Economic Club of Chicago on January 13, 2012 (almost two years after the explosion) by the [then] current CEO of BP, Bob Dudley. He stated: 'The Deepwater Horizon accident and oil spill took eleven lives, injured dozens more, and disrupted the livelihoods of people in the Gulf Coast region' (Dudley 2012, p. 94). However, the Deepwater Horizon disaster was not simply an 'accident' according to numerous observers (Elkind et al., 2011). The word 'disrupted' is far too mild. Limiting comment to 'livelihoods' is disingenuous too because it crudely ignores major health and environmental effects. Dudley (2012, p. 94) continued by claiming 'Despite our best efforts, some oil did reach the shore.' Some? Dudley makes no mention of any culpability, remote or otherwise, for the effects of 'the company's evident failure to bring the problem rapidly under control' (Breeze, 2012, p. 11). He ignores the likely on-going effects of the oil that dispersed in the waters and seabed of the Gulf of Mexico.

The leadership words in public speeches of a succession of CEOs of BP (Browne, Hayward, and Dudley) are troubling. They helped to constitute and reflect the nature of the company's culture and the rather anemic safety component of that culture. Our 
analysis has focused specifically on Hayward's 2010 AGM speech (although we did briefly consider his other eighteen public speeches, as well as the many speeches delivered by his predecessor, Lord Browne). The tentative definition of 'safety culture' introduced in section 2 ('... the ongoing construction of underlying assumptions, beliefs, values and attitudes shared by members of an organization in moving to an environment characterized by a quest for an absence of harm') accorded CEO-speak a critical role.

Within the context of our analysis of CEO Hayward's 2010 AGM, this critical role relates to what Blazsin and Guldenmund $(2015$, p.18) argue, in their discussion of safety culture construction, '...appear as ongoing, dynamic, never-ending processes', characterized by four recurring stages. Their second stage ('Interaction'), third stage ('Institutionalization'), and fourth stage ('Internalization') seem especially important with respect to CEO-speak. The ideology and metaphor of the CEO's speech as a rhetorical device could have aided in the social construction of a safety culture at BP. Our analysis did not find evidence of this in the AGM speech by CEO Hayward.

Close monitoring of the language of CEOs is important in an age of powerful global corporations. This is especially the case when many corporate leaders become insulated by extreme wealth, protected from reality by boards and colleagues, and influenced by an ideology of extreme efficiency. They lose a grip on things that matter most - such as putting in place a safe environment offering an absence of harm. 


\section{Acknowledgements}

The authors thank the anonymous reviewers and the Associate Editor for their helpful and constructive comments.

\section{References}

Amernic, J., \& Craig, R. (2001). Three tenors in perfect harmony: 'Close readings' of the joint letter by the heads of aluminium giants Alcan, Pechiney, and Alusuisse announcing their mega-merger plan. Critical Perspectives on Accounting, 12, 763795.

Amernic, J., \& Craig, R. (2006). CEO-speak: The language of corporate leadership. Montreal and Kingston: McGill-Queen's University Press..

Amernic, J., \& Craig, R. (2009). Understanding accounting through conceptual metaphor: Accounting is an instrument? Critical Perspectives on Accounting,20, 875-883.

Amernic, J., \& Craig, R. (2013). Leadership discourse, culture, and corporate ethics: CEO-Speak at News Corporation. Journal of Business Ethics, 118, 379-394.

Amernic, J., Craig, R., \& Tourish, D. (2007). The charismatic leader as pedagogue, physician, architect, commander and saint: Five root metaphors in Jack Welch's letters to shareholders of General Electric. Human Relations, 60, 1839-72.

Amernic, J., Craig, R., \& Tourish, D. (2010). Measuring and assessing tone at the top using annual report CEO letters. Edinburgh: Institute of Chartered Accountants in Scotland.

Amernic, J., Craig, R., \& Tourish, D. (2012). Reflecting a company's safety culture in 'fairly presented' financial statements: The case of BP. CPA Journal, April, 6, 8-10. 
Antonsen, S. (2009). Safety culture and the issue of power. Safety Science, 47, 183191.

Apostolides, N. (2010). Exercising corporate governance at the annual general meeting. Corporate Governance, 10, 140-149.

Baker Report. (2007). Report of the BP U.S. Refineries Independent Safety Review Panel. January, www.bp.com.

Beelitz, A., \& Merkl-Davies, D. (2012). Using discourse to restore organisational legitimacy: 'CEO-speak' after an incident in a German nuclear power plant. Journal of Business Ethics, 108, 101-120.

Berger, P.L., \& Luckman, T. (1966). The Social Construction of Reality. New York: Penguin Books.

Blaikie, N. (2007). Approaches to Social Enquiry. Cambridge, UK: Polity Press.

Blain, M. (1988). Fighting words: What we can learn from Hitler's hyperbole. Symbolic Interaction, 11(2), 257-276.

Blazsin, H., \& Guldenmund, F. (2015). The social construction of safety: Comparing three realities. Safety Science, 71, 16-27.

Breeze, R. (2012). Legitimation in corporate discourse: Oil corporations after Deepwater Horizon. Discourse \& Society, 23, 3-18.

Brennan, N.M., \& Conroy, J.P. (2013). Executive hubris: The case of a bank CEO. Accounting, Auditing \& Accountability Journal, 26, 172-195. 
Catasús, B., \& Johed, G. (2007). Annual general meetings - rituals of closure or ideal speech situations? A dual analysis. Scandinavian Journal of Management, 23, 168190.

Cheney, G. (1998). 'It's the economy stupid!' A rhetorical-communicative perspective on today's market. Australian Journal of Communication, 25(3), 25-44.

Choudhry, R.M., Fang, D., \& Mohamed, S. (2007). The nature of safety culture: a survey of the state of the art. Safety Science, 45, 993-1012.

Cohn, J.B., \& Wardlaw, M.I. (2016). Financing constraints and workplace safety. Journal of Finance, $L X X /(5), 2017-2057$.

Collinson, D.L. (1999). 'Surviving the rigs': Safety and surveillance on North Sea oil installations. Organization Studies, 20, 579-600.

Craig, R., \& Amernic, J. (2004). Enron discourse: The rhetoric of a resilient capitalism. Critical Perspectives on Accounting, 15 (6/7), 813-852.

Craig, R., Mortensen, T., \& Iyer, S. (2012). Exploring top management language for signals of possible deception: The words of Satyam's chair Ramalinga Raju. Journal of Business Ethics, 113, 333-347.

Crooks, E. (2010). Dudley vows new BP safety culture. Financial Times, July 27, http://www.ft.com/cms/s/0/ab15d58e-994c-11df-983400144feab49a.html?ftcamp=rss; accessed 28 July 2010.

Dudley, R.W. (2012). A safer, stronger BP: Our quest to earn back America's trust. Vital Speeches of the Day, March, 93-97. Address by Robert W. Dudley, Group Chief Executive, BP, Economic Club of Chicago, 2012; Jan. 13. 
Dunn, S. (1990). Root metaphor in the old and new industrial relations. British Journal of Industrial Relations, 28, 1-31.

Eagleton, T. (1991). Ideology: An introduction. Verso, UK.

Edwards, J.R.D., Davey, J., \& Armstrong, K. (2013). Returning to the roots of culture: A review and re-conceptualization of safety culture. Safety Science, 55, 70-80.

Elkind, P,, Whitford, D., \& Burke, D. (2011). BP: An accident waiting to happen. FORTUNE, January 24.

Fairclough, N. (1992). Language and power. White Plains, NY: Longman.

Foucault, M. (1979). Discipline and punish: The birth of the prison. Hammondsworth, UK: Penguin.

Gergen, K. (2001). Social construction in context. London, Sage.

Gibbs, Jr. R.W. (2015). Counting metaphors: What does this reveal about language and thought? Cognitive Semantics, 1, 155-177.

Gilbert, D., \& Scheck, J. (2014). BP found grossly negligent in Deepwater Horizon disaster. Wall Street Journal, http://online.wsj.com/articles/u-s-judge-finds-bpgrossly-negligent-in-2010-deepwater-horizondisaster-1409842182

Guldenmund, F.W. (2000). The nature of safety culture: A review of theory and research. Safety Science, 34, 215-257.

Harrington, A. (1995). Metaphoric connections: Holistic science in the shadow of the Third Reich. Social Research, 62(2), 357-385.

Hart, R.P., Jarvis, S.E., Jennings, W.P., \& Smith-Howell, D. (2005). Political keywords: Using language that uses us. New York, NY: Oxford University Press. 
Haukelid, K. (2008). Theories of (safety) culture revisited - an anthropological approach. Safety Science, 46, 413-426.

Hopkins, A. (2006). Counteracting the cultural causes of disaster. Journal of Contingencies and Crisis Management, 7, 141-149.

Lakoff, G., \& Johnson, M. (1980). Metaphors we live by. Chicago and London: The University of Chicago Press.

Landau, M.(1961). On the use of metaphor in political analysis. Social Research, 28(3), 331-353.

Lanham, R.A. (1993). The electronic word: Democracy, technology, and the arts. Chicago, Illinois: University of Chicago Press.

Lanham, R.A. (2006). The economics of attention: Style and substance in the age of information. Chicago, Illinois: University of Chicago Press.

Leibbrand, M.P. (2015). The language of executive financial discourse. Studies in Communication Sciences, $15,45-52$

Lye, J. (2008). Ideology: A brief guide. Online at http://www.brocku.ca/ english/jlye/ideology.html; last updated 2008.

Martin, J. (1990). Deconstructing organizational taboos: The suppression of gender conflict in organizations. Organization Science, 1, 339-59.

McDermott, W.B. (1990). The future as metaphor. Futures, 20(2), 191-202.

Obama, B. (2010). Remarks by the President to the nation on the BP oil spill. 2010: June 15, http://www.whitehouse.gov/the-press-office/remarks-president-nation-bpoil-spill, accessed 1 July 2012. 
Ocasio, W. (2005). The opacity of risk: Language and the culture of safety in NASA's space shuttle program. In: W.H Starbuck and M. Farjoun, eds. Organization at the limit: Lessons from the Columbia Disaster, Malden, MA: Blackwell, 101-121.

Oswald, S., \& Rihs, A. (2014). Metaphor as argument: Rhetorical and epistemic advantages of extended metaphors. Argumentation, 28, 133-159.

Palaima, T. (2009). The tools of power. Times Higher Education, 2 April: online at http://www.timeshighereducation.co.uk/story.asp?storycode=406001; accessed May 15, 2011.

Pant, D.R, \& Alberti, F. (1997). Anthropology and business: Reflections on the business applications of cultural anthropology. Liu Papers n. 42, Serie Economia e Impressa, 11, giugno, 1-25.

Perelman, C., \& Olbrechts-Tyteca, L. (1958). The new rhetoric: A treatise on argumentation. Notre Dame, IN: Notre Dame Press; 1969 reprint.

Pérez, L.A. (2008). Cuba in the American imagination: Metaphor and the imperial ethos. Chapel Hill: University of North Carolina Press.

Phillips, N., Lawrence, T., Hardy, C. (2004). Discourse and institutions. Academy of Management Review, 29, 1-18.

Porter, M.E, \& Nohria, N. (2010). What is leadership? The CEO's role in large, complex organizations, in HANDBOOK OF LEADERSHIP THEORY AND PRACTICE An HBS Centennial Colloquium on Advancing Leadership EDITED BY Nohria N, Khurana R. Harvard Business Press BOSTON, MASSACHUSETTS, 433-473

Rasmussen, J. (2011). Enabling selves to conduct themselves safely: Safety committee discourse as governmentality in practice. Human Relations, 64(3), 459-478. 
Reilly, W.K. (2010). National Commission on the BP Deepwater Horizon oil spill and offshore drilling. 5th meeting, November 8-9, Washington, D.C., meeting minutes.

Ricoeur, P. (1977). The rule of metaphor. Toronto; Buffalo : University of Toronto Press; (translated by Robert Czerny, with Kathleen McLaughlin and John Costello).

Ricoeur, P. (2016). Hermeneutics and the human sciences. Cambridge University Press; (originally published 1981; edited, translated, and introduced by John B. Thompson).Rohrer, T., and Vignone, M.J. (2012). The bankers go to Washington: Theory and method in conceptual metaphor analysis. Nouveaux cahiers de linguistique française, 30, 5-38

Ron, A. (2008). Power. A pragmatist, deliberative (and radical) view. Journal of Political Philosophy, 16, 272-292.

Scheff, T.J. (1997). Emotions, the social bond, and human reality: Part/whole analysis. Cambridge University Press.

Schein, E. (2004). Organizational culture and leadership. New York, NY: Wiley.

Schneider, M.J. (1998). The Wal-Mart annual meeting: From small-town America to global corporate culture. Human Organization, 57, 292-299.

Schön, D.A. (1993). Generative metaphor: A perspective on problem-solving in social policy. In A. Ortony (Ed), Metaphor and thought. New York: Cambridge University Press, 137-163.

Silbey, S. (2009). Taming Prometheus: Talk about safety and culture. Annual Review of Sociology, 35, 341-369.

Sissell, K.(2010). Looking back at BP Texas City. Chemical Week,March 22/29: 39. 
Slagell, A.R. (1991). Anatomy of a masterpiece: A close textual analysis of Abraham Lincoln's second inaugural address. Communication Studies, 42(2), 155-171.

Steffy, L.C. (2011). Drowning in Oil: BP and the reckless pursuit of profit. New York, NY: McGraw-Hill.

Steger, T. The stories metaphors tell: Metaphors as a tool to decipher tacit aspects in narratives. Field Methods 2007; 19(1): 3-23.

Stout, L. (2012). The shareholder value myth. San Francisco: Berrett-Koehler Publishers.

Thornton, D.B. (1988). Theory and metaphor in accounting. Accounting Horizons, 2(4), $1-9$.

Tinker, T. (1986). Metaphor or reification: Are radical humanists really libertarian anarchists? Journal of Management Studies, 23(4), 363-384.

Tucker, S., Ogunfowora, B., \& Her, D. (2016). Safety in the C-suite: How chief executive officers influence organizational safety climate and employee injuries. Journal of Applied Psychology, 101(9), 1228-1239.

Turner, N., \& Gray, G.C. (2009). Socially constructing safety. Human Relations, 62(9), 1259-1266.

U.S. Chemical Safety and Hazard Investigation Board. (2007). Investigation report. Report No. 2005-04-I-Tx, Refinery explosion and fire. March, http://www.csb.gov/assets/document/CSBFinalReportBP.pdf, accessed 1 July 2012.

Walters-York, L.M. (1996). Metaphor in accounting discourse. Accounting, Auditing \& Accountability Journal, 9(5), $45-70$. 
Weick, K. E.(1995). Sensemaking in organizations. Thousand Oaks, CA: Sage.

Weick, K., \& Sutcliffe, K. (2007). Managing the unexpected: Resilient performance in an age of uncertainty. San Francisco, CA: Jossey Bass.

Werth, P. (1994). Extended metaphor - a text-world account. Language and Literature, 3(2), $79-103$

Williams, R. (1976). Keywords: a vocabulary of culture and society. London, UK: Fontana.

Young, J.J. (2013). Devil's advocate: The importance of metaphors. Accounting Horizons, 27(4), 877-886. 


\section{Appendix A}

CEO Hayward's Corpus of Eighteen Speeches Prior to the 2010 AGM Speech (downloaded from www.bp.com)

\begin{tabular}{|c|c|c|c|c|}
\hline No. & Date & Title & Venue & Words \\
\hline 1 & $\begin{array}{l}\text { June 4, } \\
2007\end{array}$ & $\begin{array}{l}\text { Delivering Technologies via Carbon } \\
\text { Markets }\end{array}$ & $\begin{array}{l}\text { GLOBE Berlin } \\
\text { Legislators Forum, } \\
\text { Berlin }\end{array}$ & 2992 \\
\hline 2 & $\begin{array}{l}\text { June 11, } \\
2007\end{array}$ & $\begin{array}{l}\text { Securing the Future - An Oil Company } \\
\text { Perspective }\end{array}$ & $\begin{array}{l}\text { EAGE Annual } \\
\text { Conference London }\end{array}$ & 2203 \\
\hline 3 & $\begin{array}{l}\text { June 17, } \\
2007\end{array}$ & Investing in Russia: A BP perspective & $\begin{array}{l}\text { Investing in Prosperity } \\
\text { conference - Moscow }\end{array}$ & 2311 \\
\hline 4 & $\begin{array}{l}\text { Nov } 8 \\
2007\end{array}$ & Energy Security and America & Houston & 2000 \\
\hline 5 & $\begin{array}{l}\text { April 17, } \\
2008\end{array}$ & Speech, 2008 AGM & London & 2224 \\
\hline 6 & $\begin{array}{l}\text { June } 9 \\
2008\end{array}$ & $\begin{array}{l}\text { How to Expand Energy Supply in the } \\
\text { 21st Century }\end{array}$ & $\begin{array}{l}\text { 13th Asia Oil \& Gas } \\
\text { Conference, Kuala } \\
\text { Lumpur }\end{array}$ & 3141 \\
\hline 7 & $\begin{array}{l}\text { June 30, } \\
2008\end{array}$ & Speech at the World Petroleum Council & $\begin{array}{l}\text { World Petroleum } \\
\text { Council, Madrid }\end{array}$ & 1847 \\
\hline 8 & $\begin{array}{l}\text { July } 3 \\
2008\end{array}$ & $\begin{array}{l}\text { Speech at the London } 2012 \text { Olympic } \\
\text { Games Sponsorship event }\end{array}$ & British Museum, London & 626 \\
\hline 9 & $\begin{array}{l}\text { Nov } 25, \\
2008\end{array}$ & $\begin{array}{l}\text { Delivering Energy for Sustainable } \\
\text { Growth }\end{array}$ & $\begin{array}{l}\text { Tsinghua University, } \\
\text { Beijing }\end{array}$ & 3006 \\
\hline 10 & $\begin{array}{l}\text { Dec17, } \\
2008\end{array}$ & $\begin{array}{l}\text { Remarks, HRH Prince of Wales's 3rd } \\
\text { Annual Accounting for Sustainability } \\
\text { Forum }\end{array}$ & London & 1291 \\
\hline 11 & $\begin{array}{l}\text { Feb 10, } \\
2009\end{array}$ & $\begin{array}{l}\text { 28th CERA Executive Conference - } \\
\text { Opening speech }\end{array}$ & Houston & 2401 \\
\hline 12 & $\begin{array}{l}\text { April 16, } \\
2009\end{array}$ & Speech, 2009 AGM & $\begin{array}{l}\text { ExCel centre, } \\
\text { Docklands, London }\end{array}$ & 2205 \\
\hline
\end{tabular}




\begin{tabular}{|l|l|l|l|r|}
\hline 13 & $\begin{array}{l}\text { May 14, } \\
2009\end{array}$ & $\begin{array}{l}\text { Speech accepting the Institute's first } \\
\text { Energy Innovator Award }\end{array}$ & $\begin{array}{l}\text { Institute of The } \\
\text { Americas Conference, } \\
\text { La Jolla, California }\end{array}$ & 1746 \\
\hline 14 & $\begin{array}{l}\text { Oct 8, } \\
2009\end{array}$ & The Role of Gas in the Future of Energy & $\begin{array}{l}\text { World Gas Conference, } \\
\text { Buenos Aires }\end{array}$ & 2000 \\
\hline 15 & $\begin{array}{l}\text { Oct 20, } \\
2009\end{array}$ & Meeting the Energy Challenge & $\begin{array}{l}\text { Oil and Money } \\
\text { Conference, London }\end{array}$ & 2330 \\
\hline 16 & $\begin{array}{l}\text { Oct 29, } \\
2009\end{array}$ & $\begin{array}{l}\text { The Harsh Realities of Energy } \\
2009\end{array}$ & $\begin{array}{l}\text { MIT } \\
\text { sustainable energy future }\end{array}$ & 3275 \\
\hline 17 & $\begin{array}{l}\text { Mec 4, } 23, \\
2010\end{array}$ & Energy security through diversity & $\begin{array}{l}\text { Perld Oil and Gas } \\
\text { Assembly, Bangalore }\end{array}$ & 2635 \\
\hline 18 & & & & 2608 \\
\hline
\end{tabular}


Appendix B

Tony Hayward's Speech to the 2010 AGM [line numbers added]

See next page 
Good morning ladies and gentlemen. It's great to see so many of you here today and thank you for your support over the past year.

I'd like to start by welcoming Carl-Henric to BP and to his first AGM. As an international business leader, Carl-Henric has brought a fresh perspective and a wealth of experience to the company, and I am very much enjoying working with him.

BP has made a lot of progress over the last three years, but there's still more to do. We now have a real opportunity to make our asset base work harder for our shareholders and today I'd like to explain how we plan to make that happen.

But first let me begin by looking at the broader environment and how it is shaping our priorities. In the short term, the global downturn has reduced energy demand although we expect oil demand to grow again in 2010, probably by about a million barrels a day. And over the longer term, driven by industrialisation and rising living standards in the developing economies, global energy consumption will continue to rise.

Of course a number of big challenges lie ahead, especially in the realm of policy, where the question of how to meet rising energy demand in an affordable and sustainable way has risen to the top of the global political agenda.

For a long time now, BP has advocated a proactive approach to climate change and supported action to curb carbon emissions. And we continue to believe that the world needs a diverse energy mix that incorporates all available sources from oil sands to solar and leverages investment in technology.

Key to this is a need to promote efficiency to minimise the environmental impact of fossil fuels and to ensure we maximise best use of the world's energy resources. This will help to provide secure supplies of energy as well as addressing climate change.

We also believe that encouraging free and open energy markets is the best way to induce change. A carbon price, preferably created by capping emissions, would provide a strong incentive to encourage energy efficiency and investment in alternatives to fossil fuels.

BP is supporting the transition to a low-carbon economy in a number of ways: firstly by improving energy efficiency within our own operations, as well as by developing more efficient products such as BP Ultimate and Castrol lubricants.

Secondly, by using an internal cost of carbon when making investment decisions about fossil fuel projects. This encourages investment in technology to reduce carbon emissions.

And thirdly by promoting the lowest-cost energy pathways to reduce emissions a good example being the use of natural gas to generate power. Gas is easily the cleanest-burning fossil fuel - it's efficient, versatile and abundantly available. 
We also continue to invest in our low-carbon businesses; since 2005 we have invested more than $\$ 4$ billion in Alternative Energy, and focused our activity in four key areas:

-In Biofuels we're converting sugar cane to ethanol in Brazil. In the UK we're constructing an ethanol manufacturing plant and a technology demonstration plant for biobutanol with DuPont. And in the US we are working on the conversion of ligno-cellulosic material to biofuels. -In Wind we've focused the business in the US where we already have more than 1.2 gigawatts of gross capacity spinning. We expect this business to become cash flow positive this year. -In Solar we've focused the business and we're repositioning our manufacturing footprint to lower-cost locations, principally in India and China.

-And in Carbon Capture and Sequestration we're concentrating on two major projects - one in California, the other in Abu Dhabi.

All this is underpinned by our continuing investment in research and technology. BP currently has 20 major technology programmes underway. Around two thirds relate to existing businesses and the remainder to new forms of energy and ways of making today's energy more efficient.

Our priorities which lie at the heart of all our operations remain safety, people and performance. This is what we call our Forward Agenda. Our focus on safe and reliable operations is now strongly embedded in all our businesses; we are continuing to build the on the core capabilities of our people; and we have started to see the benefits of improved operational performance flowing through to the bottom line.

Safety remains our number one priority and I'm pleased to report we can see clear progress. There has been a significant reduction in the frequency of recordable injuries and the number of major incidents related to integrity failures has also fallen. At the same time we're reducing containment losses in our operations.

We are continuing to improve our skills and capabilities as we roll out a common Operating Management System across our business. By the end of 2009 we'd fully implemented this at 70 sites - covering around 80 per cent of our operations and the remainder will be completed this year.

But implementation is just the beginning. Our Operating Management System provides the framework to now drive continuous improvement across all of our operations.

Our people have been fundamental to the company's transformation over the last few years. Not only have we refreshed the highest levels of leadership within BP, but we have also reviewed our whole approach to the organisation. We are focussing on deepening our capability by putting the right people with the right skills in the right places. And we are ensuring they can reinforce their technical and functional expertise through development programmes like our Operations Academies.

We are continuing our drive to create a diverse and inclusive workplace to ensure that we can attract and retain the best talent. And we have linked reward more closely to performance. 
These changes have been clearly reflected in improved operational performance.

Over the last two years we have closed the competitive gap that we identified in 2007, and restored momentum in our core businesses. In 2009 we grew production by 4 per cent, building on the track record of momentum relative to our peers since 2000. In refining we have brought our US network back to full operation, and our system is now back to pre-2005 levels of availability.

The drive to increase efficiency and reduce costs remains a key focus for everyone at BP. We started more than two years ago in our effort to counter cost inflation and drive much greater efficiency into our business.

In the upstream we are leading our peer group in driving down production costs, with BP's unit costs in 200912 per cent lower than in 2008. We will maintain this momentum through activity choice and in the way we manage the supply chain. In the downstream our efficiency initiatives have reduced cash costs by more than 15 per cent in 2009 and our goal over the next 2 to 3 years is to return costs to 2004 levels. For the group as a whole we reduced our cash costs last year by more than $\$ 4$ billion.

In 2009, lower oil and gas prices and weak refining margins created a challenging environment for the whole sector. But the operational momentum in our business and our steadfast focus on efficiency has clearly improved our performance relative to our peers.

Despite a challenging year, this performance meant we could distribute $\$ 10.5$ billion to shareholders and increase our dividend to 56 cents per share. It's also been reflected in our relative share price performance since the beginning of last year; we have outperformed ALL our major competitors.

As well as delivering a good operational performance in 2009, we saw significant strategic progress across the company.

In E\&P we achieved major new access to resources and made a series of significant discoveries. We have maintained our strong track record of reserve replacement. This is our 17th consecutive year in which we are able to report a reserves replacement above 100 per cent. Year-on-year production growth was 4 per cent. We started up seven major projects and sanctioned two notable new developments.

In R\&M, our refining system has been fully restored. We decapitalised our US convenience retail business and reduced the geographic footprint of our international businesses. At the same time costs have come down by 15 per cent.

Alternative Energy is more focused and disciplined. And we have furthered our corporate simplification agenda, reducing headcount by around 7500 . 
Let me give you a little more detail on how we strengthened our portfolio of oil and gas reserves in 2009. Our discoveries included the giant Tiber oil field in the Gulf of Mexico the deepest well ever drilled in the industry. Indeed it lies further below the Earth's surface than the summit of Mount Everest does above it.

A particular highlight was our return to Iraq where we signed a contract to redevelop the supergiant Rumaila field in partnership with the Chinese National Petroleum Company. The project will help Iraqis to develop new skills as well as generate income to assist in rebuilding the country.

In the US we expanded our shale gas portfolio by securing a new position in the Eagle Ford Shale. We established a Coal Bed Methane position in Indonesia. And in Jordan we agreed to join with the National Petroleum Company to exploit the Risha gas field.

And we have continued to add resources in 2010 , most notably through the acquisition of $\$ 7$ billion worth of assets from Devon Energy that we announced last month. These include significant deepwater interests in Brazil and the Gulf of Mexico.

Over the last two years, through exploration, appraisal and access, we have added a total of around 7.5 billion barrels of new resources that's five years' worth of production replaced in just two - and that excludes Iraq.

Our strong resource base reinforces the prospects for future production growth. Last year I said that we expected to grow production between 1 and 2 per cent a year to 2013 . We are now confident that at a $\$ 60$ per barrel oil price we can sustain average production growth from 2008 at 1 to 2 per cent a year out to 2015 .

This production profile is underpinned by 42 new projects, which will start up between now and 2015. Together they will contribute around 1 million barrels a day to total production by 2015 . They are concentrated in the Gulf of Mexico, the North Sea, Azerbaijan and Angola, which are all high margin production areas.

The strategic progress that we made in 2009 is part of a longer track record. Over the past decade our strategy has allowed us to build a portfolio of great quality and huge potential: equal in our view to any in our industry in terms of the key measures shown here.

We have a long history as both an efficient and successful explorer. This has given us a reserve replacement track record which is among the best in the industry, and a long-lived asset base with a bias to conventional oil. We have confidence in robust medium term growth and considerable potential to apply new technologies to further improve recovery.

In R\&M despite a difficult environment - we have less overall exposure to refining than our peers. We have high-graded our portfolio over the past decade to end up with, on average, larger and more advantaged refineries than the other super-majors. We believe we also have the best supply optimisation capability and a set of world class international businesses. 
However while our portfolio ranks amongst the best in the industry, our financial performance has yet to fully reflect this. There is now a real opportunity to make this portfolio work harder for us and we intend to do just that.

So how do we define the opportunity? There are many ways to view it: from company-wide issues such as the gap in earnings versus our peers, to return on capital employed versus the competition; and from segment-level issues such as improving refining efficiency and closing the gap in fuels value chain performance in the US to improving efficiency in our drilling and in the execution of projects in the upstream.

Whichever way you look at it, there are significant opportunities for improvement and in every case firm plans are in place to close those gaps.

Our goal over the next few years is to realise the latent potential of our asset base by improving the efficiency and effectiveness of everything we do.

We will vigorously drive cost and capital efficiency whilst at the same time maintaining our first priority of safe and reliable operations.

In E\&P, we will drive efficiency through a new organisational structure. This will provide clearer accountabilities and a centralised approach to project management. For example, it will ensure that we use standard designs and equipment for similar projects in different parts of the world.

In R\&M, we will focus on efficiency, quality and integration as we start to realise the potential of our refinery network and restructured fuel value chains.

All of this will be underpinned by our continuing investment in technology and by the new culture we are establishing at BP.

So to sum up, our strategy remains unchanged but we are now embarking on a new phase in which we intend to realise the full potential of the portfolio we've built up over the past decade. We have considerable scope to pursue sector leadership, particularly in costs, capital efficiency and margin quality.

Of course the future looks challenging. It always does. But we have emerged from 2009 in great shape and with renewed confidence and determination. We can see the prize and we believe we are well positioned to capture it.

I want to thank the employees of BP for their commitment - and I want to thank each of you as shareholders for your loyalty and support. I hope you will continue to support us on the journey that lies ahead. Thank you. 